\title{
Diurnal Variability of Tropical Rainfall Retrieved from Combined GOES and TRMM Satellite Information
}

\author{
S. Sorooshian, X. Gao, K. Hsu, R. A. Maddox, Y. Hong, H. V. Gupta, and B. Imam \\ Department of Hydrology and Water Resources, University of Arizona, Tucson, Arizona
}

(Manuscript received 5 April 2001, in final form 29 October 2001)

\begin{abstract}
Recent progress in satellite remote-sensing techniques for precipitation estimation, along with more accurate tropical rainfall measurements from the Tropical Rainfall Measuring Mission (TRMM) Microwave Imager (TMI) and precipitation radar (PR) instruments, have made it possible to monitor tropical rainfall diurnal patterns and their intensities from satellite information. One year (August 1998-July 1999) of tropical rainfall estimates from the Precipitation Estimation from Remotely Sensed Information using Artificial Neural Networks (PERSIANN) system were used to produce monthly means of rainfall diurnal cycles at hourly and $1^{\circ} \times 1^{\circ}$ scales over a domain $\left(30^{\circ} \mathrm{S}-30^{\circ} \mathrm{N}, 80^{\circ} \mathrm{E}-10^{\circ} \mathrm{W}\right)$ from the Americas across the Pacific Ocean to Australia and eastern Asia.

The results demonstrate pronounced diurnal variability of tropical rainfall intensity at synoptic and regional scales. Seasonal signals of diurnal rainfall are presented over the large domain of the tropical Pacific Ocean, especially over the ITCZ and South Pacific convergence zone (SPCZ) and neighboring continents. The regional patterns of tropical rainfall diurnal cycles are specified in the Amazon, Mexico, the Caribbean Sea, Calcutta, Bay of Bengal, Malaysia, and northern Australia. Limited validations for the results include comparisons of 1) the PERSIANN-derived diurnal cycle of rainfall at Rondonia, Brazil, with that derived from the Tropical Ocean Global Atmosphere Coupled Ocean-Atmosphere Response Experiment (TOGA COARE) radar data; 2) the PERSIANN diurnal cycle of rainfall over the western Pacific Ocean with that derived from the data of the optical rain gauges mounted on the TOGA-moored buoys; and 3) the monthly accumulations of rainfall samples from the orbital TMI and PR surface rainfall with the accumulations of concurrent PERSIANN estimates. These comparisons indicate that the PERSIANN-derived diurnal patterns at the selected resolutions produce estimates that are similar in magnitude and phase.
\end{abstract}

\section{Introduction}

Diurnal variability of rainfall is an important aspect of regional climates to fully understand the climate systems. When precipitation occurs regularly during particular time periods of the day the atmospheric system usually is characterized by conditions and physical processes that suggest strong convection during the favored periods. Such processes include intense surface heating, the advance of a sea breeze front, the convergence of sea-land breezes, mountain and valley winds, interactions of local circulations with synoptic flows, and perhaps nighttime cooling of cloud tops to promote atmospheric instability. Many previous studies have described and analyzed diurnal cycles of rainfall and cloudiness over specific regions. However, the lack of accurate precipitation data measured at the required time scales and space scales has limited and continues to hinder further progress. The recent advances in the technology of satellite precipitation estimation make it pos-

Corresponding author address: Dr. S. Sorooshian, Department of Hydrology and Water Resources, University of Arizona, P.O. Box 210011, Tucson, AZ 85721-0011.

E-mail: soroosh@hwr.arizona.edu sible to study diurnal variations of global precipitation in much improved detail.

With limited local meteorological observations, early studies related precipitation variability to diurnal and semidiurnal atmospheric tides of temperature, pressure, and winds (Riehl 1947; Brier 1965). For example, Brier and Simpson (1969) analyzed the pressure and weather data over Batavia and Wake Island in the tropical Pacific Ocean. They found that the semidiurnal solar atmospheric tide enhanced rainfall and cloudiness near sunrise and sunset and suppressed them shortly after midday and midnight through time-varying convergence fields. When systematic data collected from weather stations on land, atolls, and weather ships, especially sounding data and satellite photos from the Global Atmospheric Research Programme (GARP) Atlantic Tropical Experiment (GATE), were available, many studies characterized the diurnal variability of rainfall over land and water. For example, using ship data, Kraus (1963) found that the frequency of nighttime [2100-0600 Local Sun Time (LST)] storms over the Atlantic and Pacific Oceans was twice that in the daytime (0900-1800 LST). He postulated that, during the day, solar heating reduces liquid water contents in the atmosphere; at night, on the 
other hand, radiative cooling is stronger at cloud tops than at the cloud bases, which could increase instability and produce deeper convection and rainfall. Gray and Jacobson (1977) found that heavy rainfall in the west Pacific and west Atlantic Oceans is $2-3$ times greater in the morning than in the late afternoon/evening. They attributed the difference to the day versus night variations in tropospheric radiative cooling between convective weather systems and the surrounding cloud-free regions. Wallace (1975) addressed the geographical patterns of precipitation diurnal frequency in the United States based on long-term hourly precipitation station data. He interpreted the patterns with three physical processes: 1) land-sea breezes, 2) the diurnal heating cycle in mountainous terrain, and 3 ) changes in frictional drag associated with the diurnal variation in static stability within the boundary layer. Recently, Dai (2001) used 15000 stations around the world to document the diurnal variations of global precipitation and thunderstorm frequency.

Satellite multispectral images of clouds provide a new opportunity to study global rainfall and cloudiness and can give much broader spatial documentation of the diurnal cycle of convective precipitation. Using cloud infrared imagery from geostationary satellites, Meisner and Arkin (1987) reported that the summertime diurnal cycle over tropical continents is much stronger than that over tropical oceans. They also found that the oceanic diurnal cycle was evident only in the ITCZ and South Pacific convergence zone (SPCZ) with near-noontime maximums. Shin et al. (1990) analyzed 3-hourly histograms of the Geostationary Operational Environmental Satellite (GOES) infrared brightness temperature $\left(T_{b}\right)$ and found that the 24-h harmonic of oceanic rainfall has peaks in the early and late afternoon over the central Pacific Ocean. However, in certain regions, such as the SPCZ and ITCZ, the 12-h harmonic with peaks at 0600 and 1800 LST was also significant. Sharma et al. (1991) and Chang et al. (1995) used Special Sensor Microwave Imager (SSM/I) microwave rainfall data to estimate that the ratio of morning to afternoon rainfall over oceans was around 1.2, instead of 2-3 as reported by Gray and Jacobson (1977). Mapes and Houze (1993) found that the development of very cold clouds $\left(T_{b}<208 \mathrm{~K}\right)$ is a sun-synchronous process, which peaks at dawn and decreases throughout the morning. The development of large moderately cold clouds $\left(T_{b}<-38^{\circ} \mathrm{C}\right)$, on the other hand, peaks in the afternoon, while small moderately cold clouds showed little diurnal variability. Janowiak et al. (1994) used the spatial fractional coverage of cold cloudiness at $2.5^{\circ} \times 2.5^{\circ}$ grid resolution determined from satellite infrared imagery as a proxy for tropical convective precipitation and found that cold clouds are most frequently observed over land between 1800 and 2100 LST and that the peak cold cloud $(<215 \mathrm{~K})$ occurrence over the Pacific Ocean is between 0300 and 0600 LST. In comparison with the previous work of Negri et al. (1994) using microwave rainfall data, Gar- reaud and Wallace (1997) described the climatological diurnal variability of convective cloudiness over the tropical and subtropical Americas at 3-hourly and $0.5^{\circ}$ $\times 0.5^{\circ}$ resolutions, based on the temporal fractional cold cloud $\left(T_{b}<-38^{\circ} \mathrm{C}\right)$ coverage of GOES infrared images. The highest frequency of cloudiness was found parallel to the coastlines of northeastern South America and the main topographic barriers of the Andes Mountains and Sierra Madre Occidental. Over the flat central part of South America, a conspicuously banded pattern of areas of maximum afternoon/evening convective cloudiness indicated a possible remote response to convectively generated gravity waves. Offshore, near-coastal regions were observed to have marked diurnal variability strongly influenced by land-sea breezes, in contrast to the much weaker diurnal feature over the open ocean in the ITCZ. Recently, Negri et al. (2000) also described the rainfall diurnal features in Amazon when they analyzed 10-yr climatology of Amazonian rainfall using satellite microwave data.

Observed features of precipitation diurnal cycles have been used to examine physical processes in atmospheric models and to diagnose model deficiencies. Randall et al. (1991) used the University of California at Los Angeles/Colorado State University general circulation model (GCM) to investigate causes of the diurnal cycle of precipitation over the oceans. They found that the oceanic diurnal cycle of the morning maximum occurs even in the absence of neighboring continents, but is much weaker when the radiative effects of clouds are omitted. They indicated that using diurnal features to test GCMs has the advantage of obtaining meaningful results with relatively short simulations. Dai et al. (1999) analyzed the diurnal patterns of precipitation simulated from the National Center for Atmospheric Research (NCAR) regional climate model (RegCM) and found substantial weaknesses in modeling diurnal patterns of precipitation (in comparison with the hourly rain gauge data over the United States) using all three available cumulus convection schemes (Grell, Kuo, CCM3). The model deficiencies in predicting precipitation diurnal variability were related to problems in the convective parameterization and were also traced back to problems in the cloud microphysics scheme that tends to overestimate cloud liquid water. Dai et al. (1999) recommended that more attention be devoted to the simulation of the diurnal cycle of precipitation in model evaluation.

With progress in the satellite remote-sensing techniques of precipitation estimation, especially the availability of superior quality TMI and PR surface rainfall data, large-scale patterns of rainfall can be monitored using rainfall estimates at improved accuracy and spatial/temporal resolutions, rather than using cold cloudiness as a proxy. The uncertainties and difficulties associated with satellite rainfall estimation are well known. In general, rainfall estimation algorithms based on infrared images from geostationary satellites benefit 
from the high frequency of monitoring, while, at the same time, use only information on cloud-top temperature to determine surface rainfall. On the other hand, microwave sensors, which are commonly installed on low-orbiting satellites, obtain measurements that reflect the distribution of hydrometeors within the cloud. Therefore, rainfall estimates based on microwave imagery explain instantaneous rainfall more realistically, yet only twice a day for any location. Many recent studies in the literature (Adler et al. 1993, 1994; Hsu et al. 1997; Xu et al. 1999, 2000; Anagnostou et al. 1999; Negri et al. 2002, etc.) have suggested that a combination of multiple sources of satellite data could improve both the accuracy and resolution of rain estimation.

In this paper, we describe the diurnal variability of rainfall from August 1998 through July 1999 over a large tropical and subtropical region $\left(30^{\circ} \mathrm{S}-30^{\circ} \mathrm{N}, 80^{\circ} \mathrm{E}-\right.$ $10^{\circ} \mathrm{W}$ ) extending from the Americas across the Pacific Ocean to Australia and eastern Asia. The diurnal cycles of tropical convective precipitation in the region are calculated as monthly means of hourly rainfall intensity (in LST) at $1^{\circ} \times 1^{\circ}$ spatial resolution. The annual variability of diurnal cycles in space and time are also illustrated at selected representative sites. The data of satellite rainfall estimates were produced by an algorithm, the Precipitation Estimation from Remotely Sensed Information using Artificial Neural Networks (PERSIANN) system (Sorooshian et al. 2000; Hsu et al. 1997; Hsu et al. 2001, manuscript submitted to Water Resour. Res.), which utilizes the high sampling frequency of geostationary satellites [GOES and the Geostationary Meteorological Satellite (GMS)] infrared cloud images and the superior quality of the low-orbiting Tropical Rainfall Measuring Mission (TRMM) microwave data. To evaluate the quality of the diurnal patterns described in the paper, limited validations were made: 1) the PERSIANN-derived diurnal cycle of rainfall at Rondonia, Brazil, was compared with that derived by Negri et al. (2001) and Anagnostou and Morales (2001) using the Tropical Ocean Global Atmosphere Coupled Ocean-Atmosphere Response Experiment (TOGA COARE) radar data; 2) the PERSIANN-derived diurnal cycle of rainfall over the western Pacific Ocean was compared with that derived by Janowiak et al. (1994) using rainfall data from optical rain gauges mounted on the TOGA-moored buoys; and 3) monthly accumulations of rainfall samples at $1^{\circ} \times 1^{\circ}$ grid resolution from the orbital TRMM Microwave Imager (TMI) and precipitation radar (PR) surface rainfall products (2A12 and 2A25) were compared with concurrent PERSIANN rainfall.

\section{Data processing}

The elemental data used in this work are 1 year (August $1998-J u l y ~ 1999)$ of half-hourly, $0.25^{\circ} \times 0.25^{\circ}$ tropical rain rates $\left(\mathrm{mm} \mathrm{h}^{-1}\right)$ produced by the PERSIANN system. The coverage region of the data is the tropical area of $30^{\circ} \mathrm{S}-30^{\circ} \mathrm{N}$ and $80^{\circ} \mathrm{E}-10^{\circ} \mathrm{W}$, which is well sampled by three geostationary satellites (GOES-9, GOES10 , and GMS-5), as well as the TRMM low-orbiting satellite. The PERSIANN system uses the infrared brightness temperature of clouds and its spatial variations from the geostationary satellites as the basic input information to retrieve the surface rain rates. There are three specific features designed in PERSIANN to improve rainfall estimation. First, because the cloud-rainfall relationship over land is different from that over ocean, the underlying surface type (land or water) for a cloud pixel is used as an additional input variable. Second, through the training (or calibration) procedure, the PERSIANN system classifies the input features into a number of clusters and sets up different submodels (relationships) for these clusters to improve the accuracy of rain-rate estimation. Third, PERSIANN possesses the function of adaptability, that is, the submodel (relationship) can make self-adjustments according to the feedback from its rainfall estimation errors and continuously improve the performance during operation. Currently, the estimation domain is divided into 60 rectangular areas $\left(15^{\circ} \times 70^{\circ}\right.$ latitude-longitude, with overlap on the edges) for parallel computation. In each area, PERSIANN creates 225 input clusters and sets up 225 cloudrainfall relationships to estimate surface rain rates. The initial submodel calibrations use 12 months (1998) of radar data over Florida; afterward, the submodels rely on the adaptability function to trace the variations of rainfall. The orbital instantaneous rain rates from TMI (product 2A12) are considered as superior measurements of surface rainfall and are used to determine estimation errors of PERSIANN. In the operational PERSIANN (with two days' delay to obtain the satellite data, published online at http://hydis.hwr.Arizona.edu/precip/ index.html), when the TMI rain (or no rain) rates are received, they are compared with the concurrent PERSIANN estimate at the same grids and the error information feedback into the responsible submodels to make model adjustments to reduce the errors. This continuously correcting procedure allows the model to follow the seasonal and regional variability of rainfall. More detailed information about the PERSIANN system and the dataset can be found in Sorooshian et al. (2000), Hsu et al. (1997), and Hsu et al. (2001, manuscript submitted to Water Resour. Res.).

To obtain the diurnal variability, the elemental (hourly $0.25^{\circ} \times 0.25^{\circ}$ ) rain rates from PERSIANN (in UTC) are first remapped to the LST according to the geographical location of each grid box (hereafter, all the time is in LST and the abbreviation is omitted). The monthly mean of rain rate $\left(\mathrm{mm} \mathrm{h}^{-1}\right)$ for a grid box in a time interval of $n$ hours is calculated from the available elemental PERSIANN data during the days of the month: 


$$
\bar{r}=\frac{1}{m n p} \sum_{j=1}^{m} \sum_{i=1}^{n} \sum_{k=1}^{p} r_{i, j, k},
$$

where $r_{i, j, k}=$ elemental $\left(0.5 \mathrm{~h}, 0.25^{\circ} \times 0.25^{\circ}\right)$ rain rate $\left(\mathrm{mm} \mathrm{h}^{-1}\right)$ estimated by PERSIANN, $m=$ total number of $0.25^{\circ} \times 0.25^{\circ}$ elements included in the grid box, $n$ $=$ total number of half hours for the time interval, and $p=$ total number of days in the month.

In the ideal case without missing data, a $1^{\circ} \times 1^{\circ}$ grid box in a 3-h interval for a month of 30 days has 2880 (i.e., $4 \times 4 \times 6 \times 30$ ) elemental rainfall samples to calculate the monthly average. For the purpose of quality control, only a grid box with more than $60 \%$ of the maximum possible rainfall samples will be processed; otherwise, the grid box is given a flag of "missing data."

\section{Limited validations}

Because of the lack of independent observations of tropical rainfall data over such a large region, only limited validation data are available to check the quality of the diurnal variations derived from the PERSIANN data. The high-resolution (approximately $15 \mathrm{~min}$ and $2 \mathrm{~km}$ ) rainfall estimates at Rondonia, Brazil, from the TOGA radar during 7 January-28 February 1999, were used to evaluate the PERSIANN daily rainfall and PERSIANN-derived diurnal cycle. According to the previous studies of Negri et al. (2002) and Anagnostou and Morales (2002), the radar data provide reliable hourly rainfall estimates for three $1^{\circ} \times 1^{\circ}$ boxes, as shown in Fig. 1a. In Fig. 1b, the correlation (CORR) between the two datasets for the three boxes ranges from 0.68 to 0.77 , with root-mean-square error (rmse) around 5.0$6.6 \mathrm{~mm} \mathrm{day}^{-1}$ and bias from -3.7 to $-1.07 \mathrm{~mm} \mathrm{day}^{-1}$ (underestimated).

In Fig. 1c, the 2-month mean diurnal cycles over the 3 boxes derived from the radar and PERSIANN rainfall data are plotted. In general, the PERSIANN estimate (similar to Fig. 10 of Anagnostou et al. 1999) captures the shape of the diurnal variability, but the maximum rainfall exhibits a delay of $1 \mathrm{~h}$ and a 2-h extension of high rainfall duration probably due to contamination by very cold anvil cirrus clouds. In comparison to the radar estimates, PERSIANN rainfall also exhibits about 0.2 $\mathrm{mm} \mathrm{h} \mathrm{h}^{-1}$ underestimation of rainfall intensity during the late night and morning (0200-1100) and about $0.3 \mathrm{~mm}$ $\mathrm{h}^{-1}$ overestimation during the afternoon and nighttime (1400-1900). Again, the afternoon overestimate is likely due to contamination by anvil cirrus clouds, and the underestimates during the late night and morning are probably due to weak and warmer-topped convective towers producing rainfall. Negri et al. (2002) presented somewhat similar results for their comparison of the estimates from the convective-stratiform technique (CST)/TMI satellite technique (Adler and Negri 1988; Negri et al. 2002). The CST/TMI data better capture the diurnal peak of rainfall over the Amazon region, but performance statistics for CST/TMI and PERSIANN for daily rain rate are very similar.

Janowiak et al. (1994) derived diurnal cycles of tropical rainfall using data from optical rain gauges mounted on the TOGA-moored buoys over the western Pacific Ocean. The rainfall data from five optical rain gauges during November 1992-February 1993 were divided into three categories according to the rain amounts in the 3-h intervals (light: 1-3 mm, medium: 4-44 mm, and heavy $>44 \mathrm{~mm}$ ) and plotted accordingly as three diurnal cycles (see Figs. 2 and 10 in their paper for the gauge locations and the diurnal cycles). In Fig. 2 (this paper), similar diurnal cycles of tropical rainfall are derived from the PERSIANN estimates during the same months (but for a different year) over the same sites $\left(2^{\circ} \mathrm{S}-2^{\circ} \mathrm{N}, 153^{\circ}-159^{\circ} \mathrm{E}\right)$. The diurnal curves from PERSIANN and TOGA gauge data show the same peak rainfall at 0300 and low rainfall occurrence at 09001200 for heavy and medium rainfall. However, the PERSIANN value at 0000 is larger than the TOGA gauge value, and the values at 0900-1200 are smaller. Although rainfall in different years may cause the difference, Janowiak et al. (1994) also noted that the absolute rainfall amounts from the optical gauges might include significant errors. In general, Fig. 2 indicates that the phases of the diurnal cycle over the open ocean derived from PERSIANN and Janowiak et al. (1994) match well.

In this study, the diurnal patterns of tropical rainfall are presented with monthly (or seasonal) means of hourly (or 3 hourly) rain rates at $1^{\circ} \times 1^{\circ}$ grid resolution. To evaluate the quality of these rain rates, the monthly (or seasonal) accumulations of TMI and PR rain rates (2A12 and 2A25) at each grid are compared with the accumulation of concurrent PERSIANN 30-min, $0.25^{\circ} \times$ $0.25^{\circ}$ rainfall estimates. The scatterplots of PERSIANN versus PR, PERSIANN versus TMI, and PR versus TMI rain accumulations during September, October, and November (SON) of 1998 for all grids, for land grids, and for ocean grids are plotted in Fig. 3. In the figure, the data statistics - mean, rmse, correlation, and bias-are presented on the lower-right corner of each panel, and the numbers for the concurrent Rain (R) and No-Rain (NR) samples at half-hourly and $0.25^{\circ} \times 0.25^{\circ}$ resolutions are presented on the upper-left corner. The scatterplots for other months are very similar and are not shown. In Fig. 3, the statistics indicate 1) the three rainfall datasets (PERSIANN, TMI, and PR) are highly correlated to each other, and because PERSIANN is trained by TMI, its correlation to TMI (0.90) is higher than to PR $(0.81)$; 2) in comparing the rain rates of these data, TMI overestimates PERSIANN, and PERSIANN overestimates PR (with positive bias); and 3) the mean rain rate over ocean is less than that over land; therefore, the relative bias of rainfall over ocean is larger than over land, but the corrections of the ocean rainfall between the datasets are consistently greater than the corrections over land. The sample data show that TMI can provide concurrent data, five times as many as PR, to 


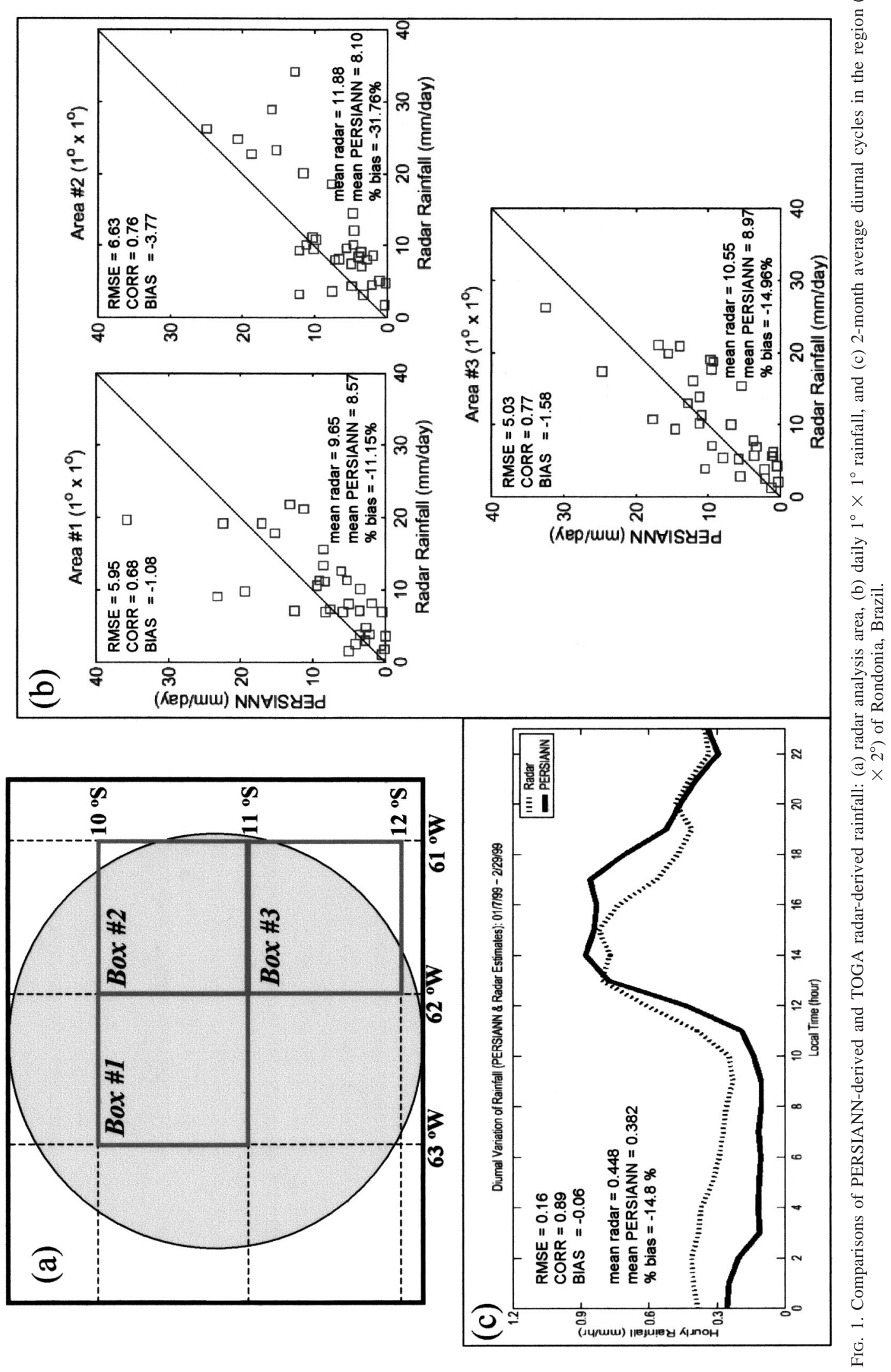



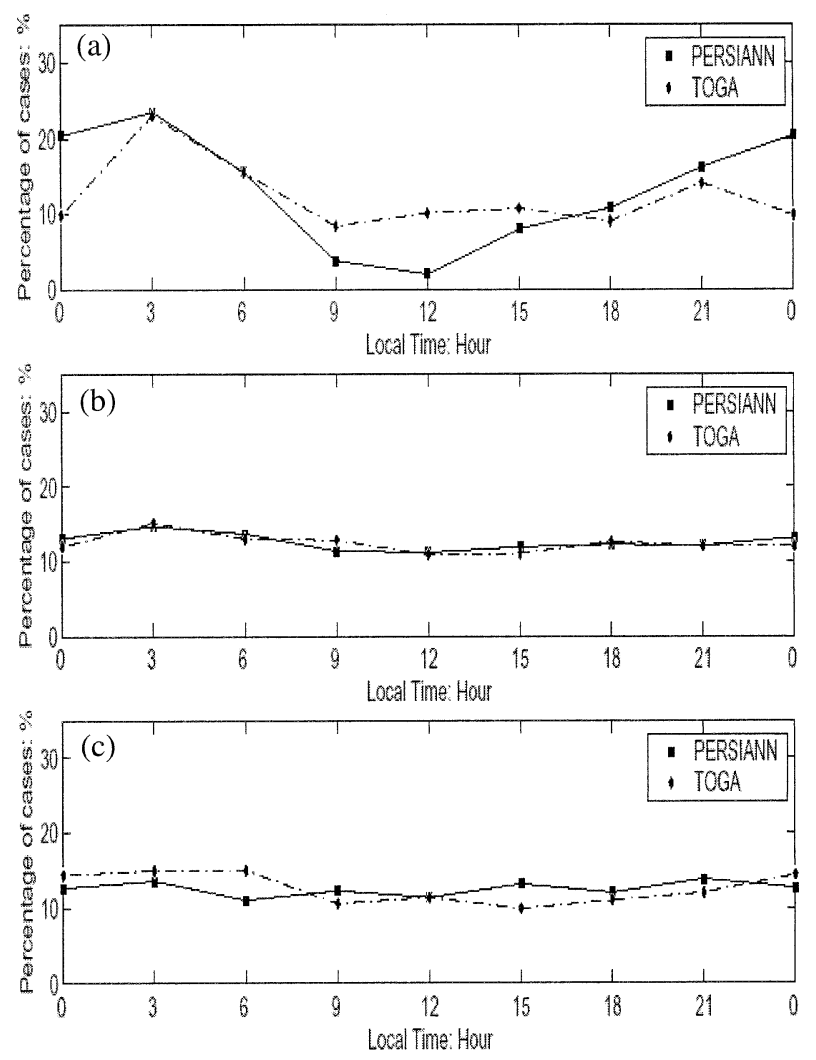

FIG. 2. Comparison of the PERSIANN-derived and TOGA rain gauge-derived diurnal cycles at $\left(2^{\circ} \mathrm{S}-2^{\circ} \mathrm{N}, 153^{\circ}-159^{\circ} \mathrm{E}\right)$ during Nov 1998-Feb 1999: (a) heavy rain, (b) medium rain, and (c) light rain.

PERSIANN for the use of calibration, and that the ratios of rain samples to total samples for PERSIANN, TMI, and $\mathrm{PR}$ are $0.08,0.06$, and 0.05 , respectively, which means that the PERSIANN rainfall may possess slight extension in space and time.

The above discussion indicates that, although PERSIANN data can be influenced by cloud type, the data provide an adequate source to study the statistical properties of the diurnal variability of precipitation at the selected spatial and temporal resolutions. In the following section, the most prominent features of diurnal variability in the Tropics are discussed.

\section{Pronounced diurnal cycles}

\section{a. Seasonal signals}

Seasonal averages of tropical rainfall at 3 -h time and $1^{\circ} \times 1^{\circ}$ space resolutions for the entire study domain (i.e., from about $40^{\circ} \mathrm{S}$ to $40^{\circ} \mathrm{N}$ and from $80^{\circ} \mathrm{E}$ to $10^{\circ} \mathrm{W}$ ) are given in Figs. 4-7. The results for June, July, and August (Fig. 4, boreal summer/austral winter) indicate a pronounced diurnal cycle over Central America, western Mexico, the extreme eastern Pacific Ocean, the Bay of Bengal, and the Maritime Continent/Southeast Asia. All of these regions are characterized by afternoon con- vection over land and nighttime to morning convection and rainfall over the oceans.

Onshore convection near the Bay of Bengal begins very early (0000-0200) in the day with distinct, new land maxima, and continuing ocean maxima present by 1200 to 1400 . While the convection decays over the ocean, the land maxima quickly intensify over northeastern India and the eastern portion of the Himalayan Plateau during 1500-1700. Convection weakens rapidly after sunset (i.e., 2100-2300).

Over western Mexico, convection develops rapidly along the Sierra Madre Occidental from 1500 to 1700 and persists until about local midnight. Over extreme southern Mexico and northern Central America, intense convection forms over the land from 1500 to 2300 and then shifts offshore after local midnight (0000-0200) off the southwestern coast of Mexico. This offshore convection grows in areal extent, appears to translate toward the southwest, and persists through midafternoon the next day. It is interesting to note that this daily cycle of convection moving offshore from southern Mexico appears to distort the ITCZ into a broad north-south zone of active convection extending westward to about $120^{\circ} \mathrm{W}$. It is only this far-eastern Pacific Ocean region of the ITCZ that displays a very strong diurnal signal in the boreal summer season. This finding, while limited to data from only one year, does not seem to agree with past studies of the diurnal cycle of tropical deep convection over the open ocean (e.g., Gray and Jacobson 1977; Meisner and Arkin 1987; Sharma et al. 1991; Janowiak et al. 1994; Chang et al. 1995). The PERSIANN results show that the diurnal signals over most of the open Pacific Ocean are of low amplitude in comparison with that over land. It is possible that a significant portion of the open-ocean rainfall occurs from warm, low-top convection (Johnson et al. 1999), which makes detection with PERSIANN difficult.

Florida, Cuba, and northern South America (Venezuela, Guyana, and the northern coast of Brazil) exhibit strong afternoon to midnight (1500-2300) convective signals over land. Any shift to offshore activity that occurs in these regions is not detected at the seasonal timescale. The Gulf of Panama shows very strong convection in the midday (0900-1400); a clear phase shift of convection to northern Colombia starts in the afternoon (1500-1700) and persists there until the early morning hours of the next day (0600). The regions south of the equator, that is, austral winter, exhibit little convective rainfall and no diurnal signals.

During December, January, and February (Fig. 5, boreal winter/austral summer), Brazil and the northern two-thirds of South America exhibit strong daytime convective rainfall signals over land that begin around local noon and extend through late night. There is no offshore late night/early morning convective rainfall associated with the South American storms. Over the Maritime Continent and northern Australia, the diurnal cycle is more pronounced during the austral summer, with over- 
(a) Land/Ocean

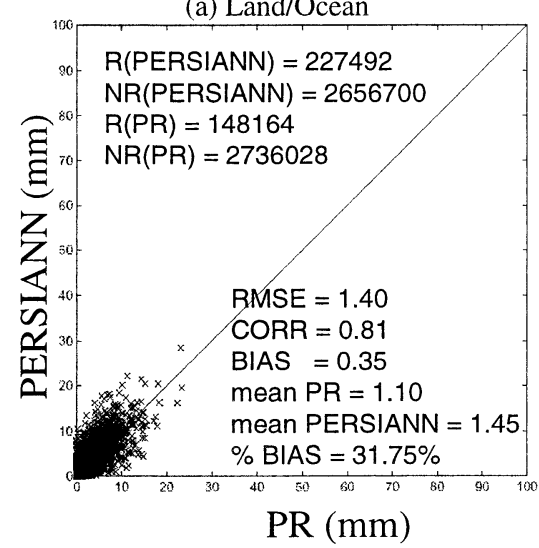

(d) Land/Ocean

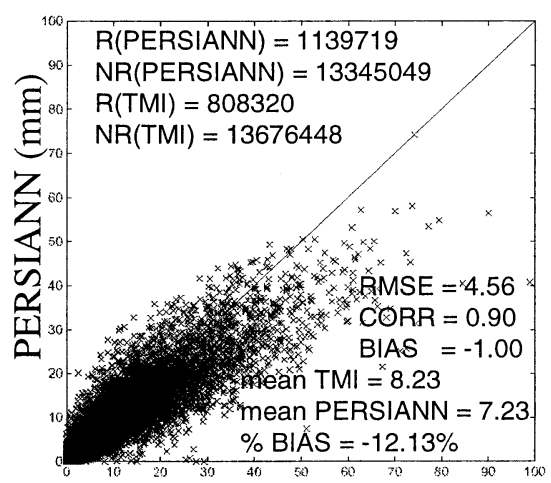

TMI (mm)

(g) Total

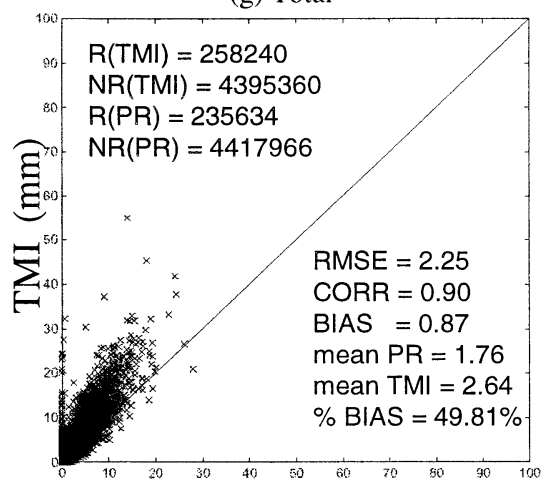

PR (mm) (b) Land

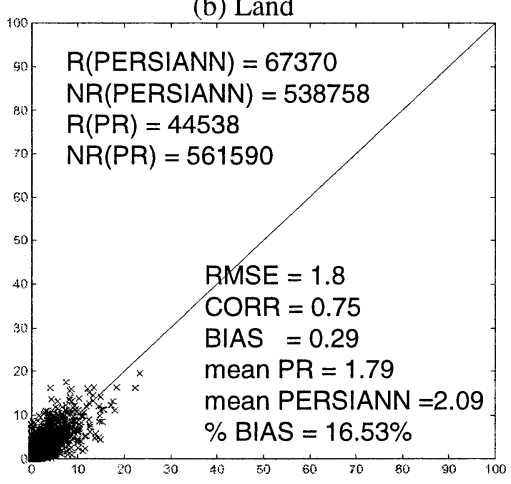

PR (mm)

(e) Land

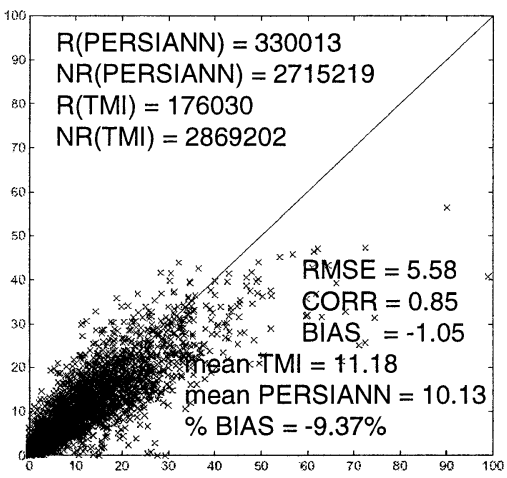

TMI (mm)

(h) Land

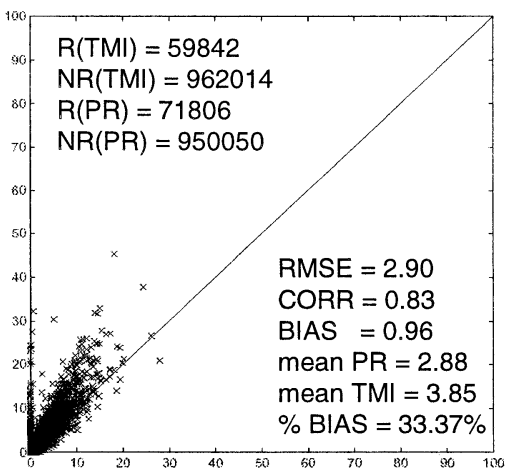

PR (mm) (c) Ocean

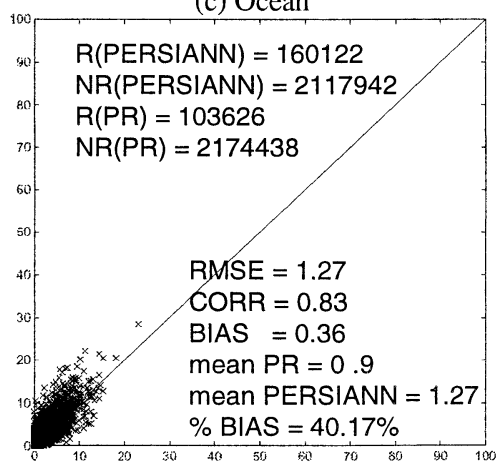

PR (mm)

(f) Ocean

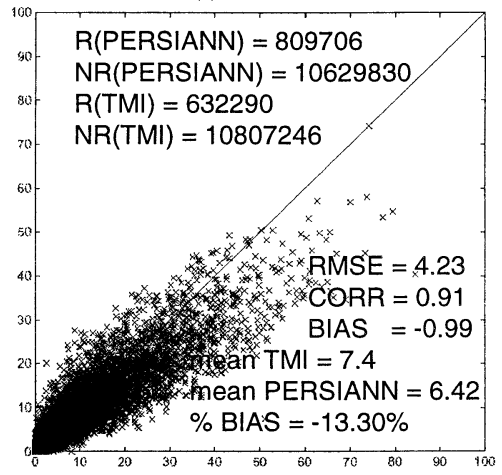

TMI (mm)

(i) Ocean

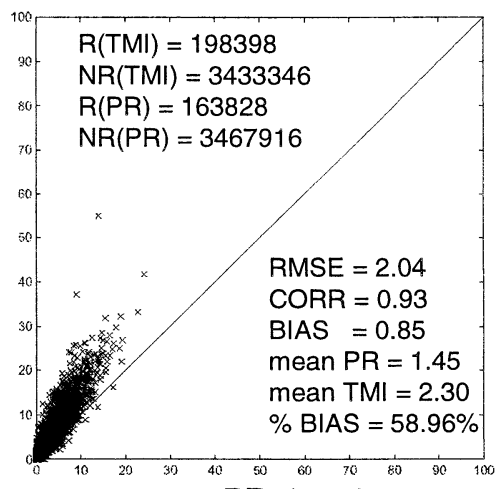

PR (mm)

FIG. 3. Comparison of rainfall accumulations from the PERSIANN vs PR, PERSIANN vs TMI, and TMI vs PR concurrent sampling pairs during SON 1998 for each $1^{\circ} \times 1^{\circ}$ grid box in the study domain: (a), (d), and (g) for all grids; (b), (e), and (h) for land grids; and (c), (f), and (i) for the ocean grids.

land convection occurring during midafternoon (15001700). This rainfall diminishes during the hours immediately after midnight (0300-0500), and then new convection develops strongly offshore between 0300 and 0600. These regions persist strongly, especially southwest of Borneo, New Guinea, and the Gulf of Carpentaria, until around noontime (1200-1400). The
SPCZ appears to stay active through most of the day, with only a mid to late afternoon (1500-2000) decrease in convective rainfall apparent. The regions north of the equator, that is, boreal winter season, exhibit little convective rainfall or diurnal signal. Notice that the ITCZ is only enhanced in the western Pacific Ocean.

During the SON transition season (Fig. 6), Central 

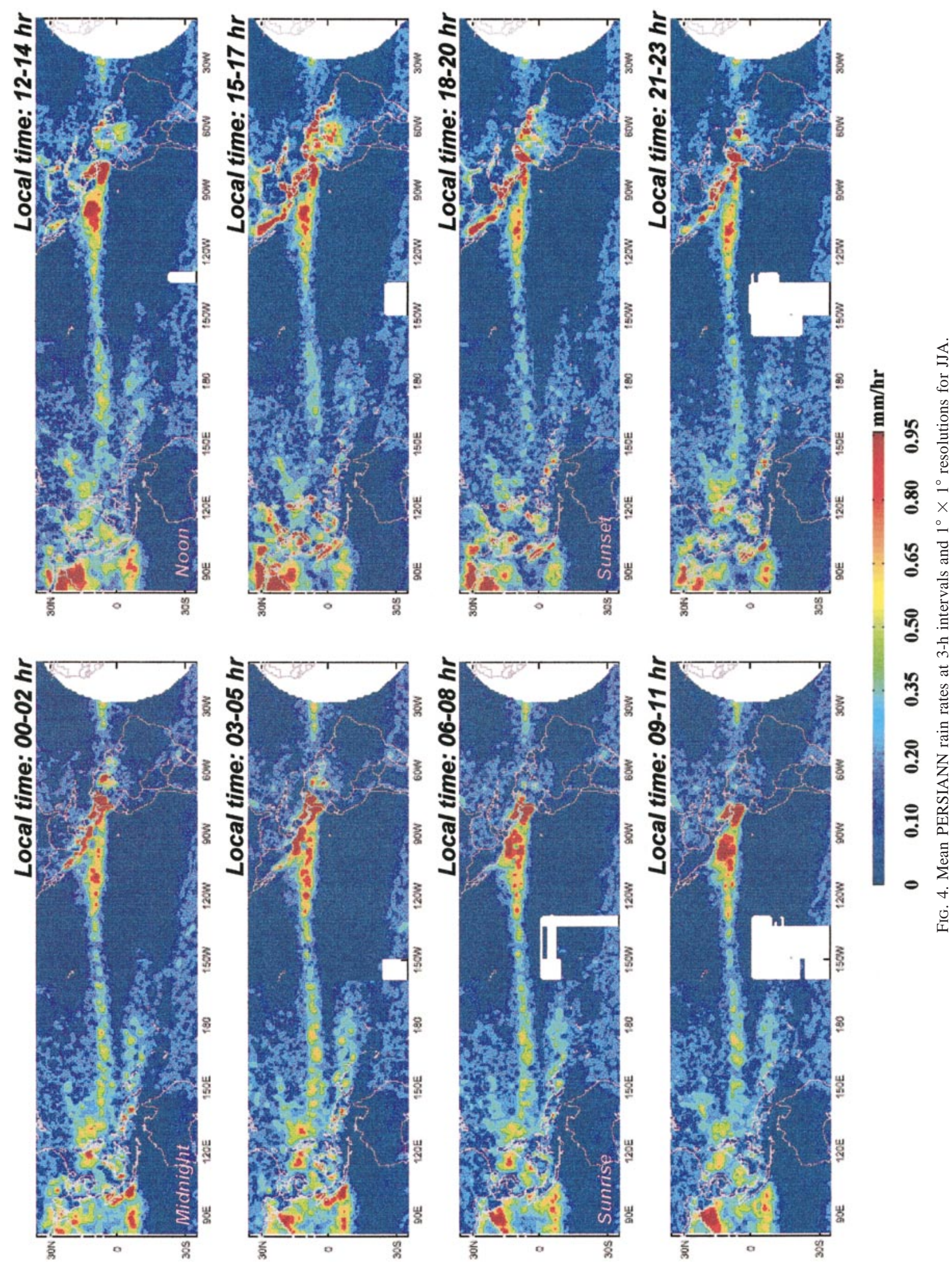

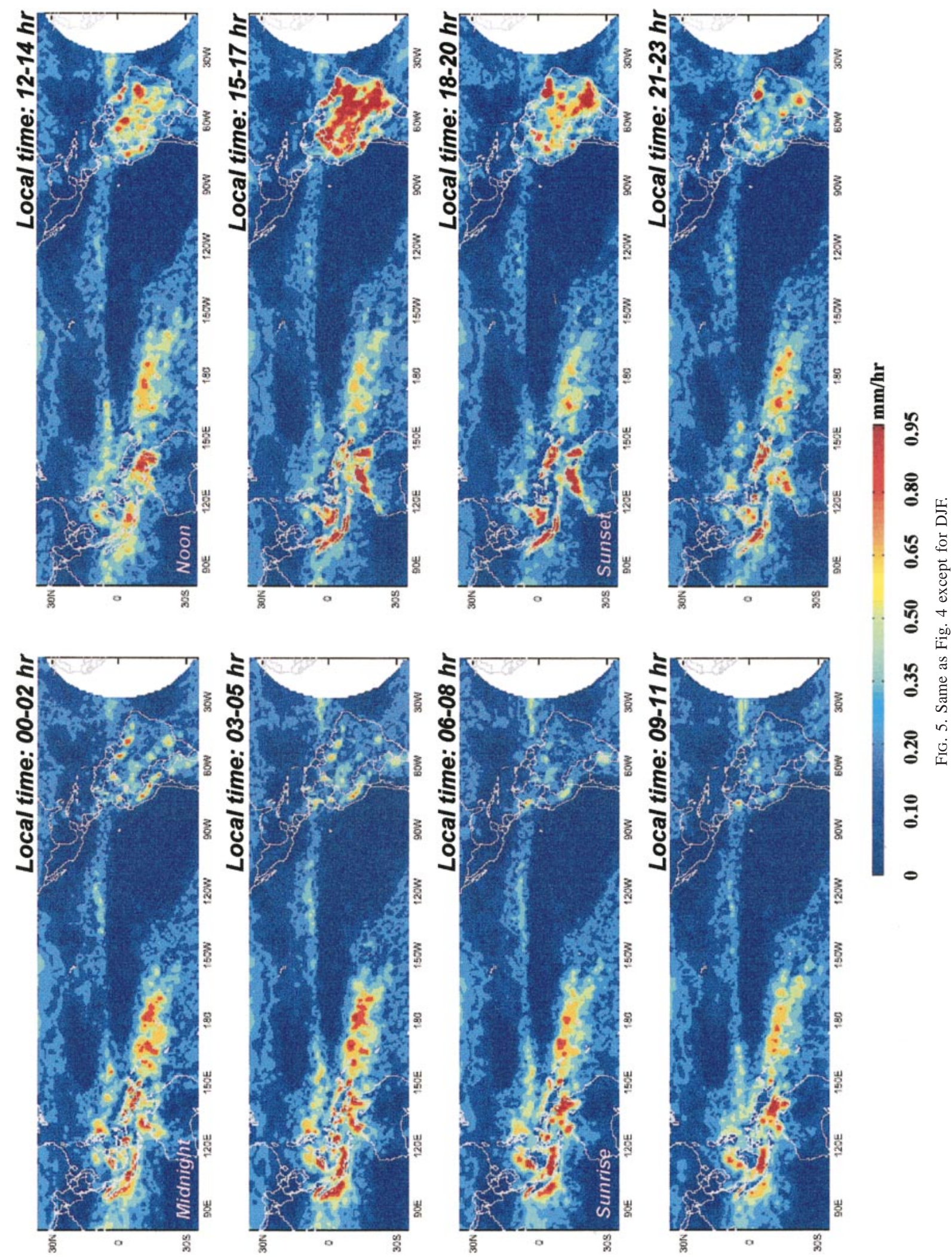

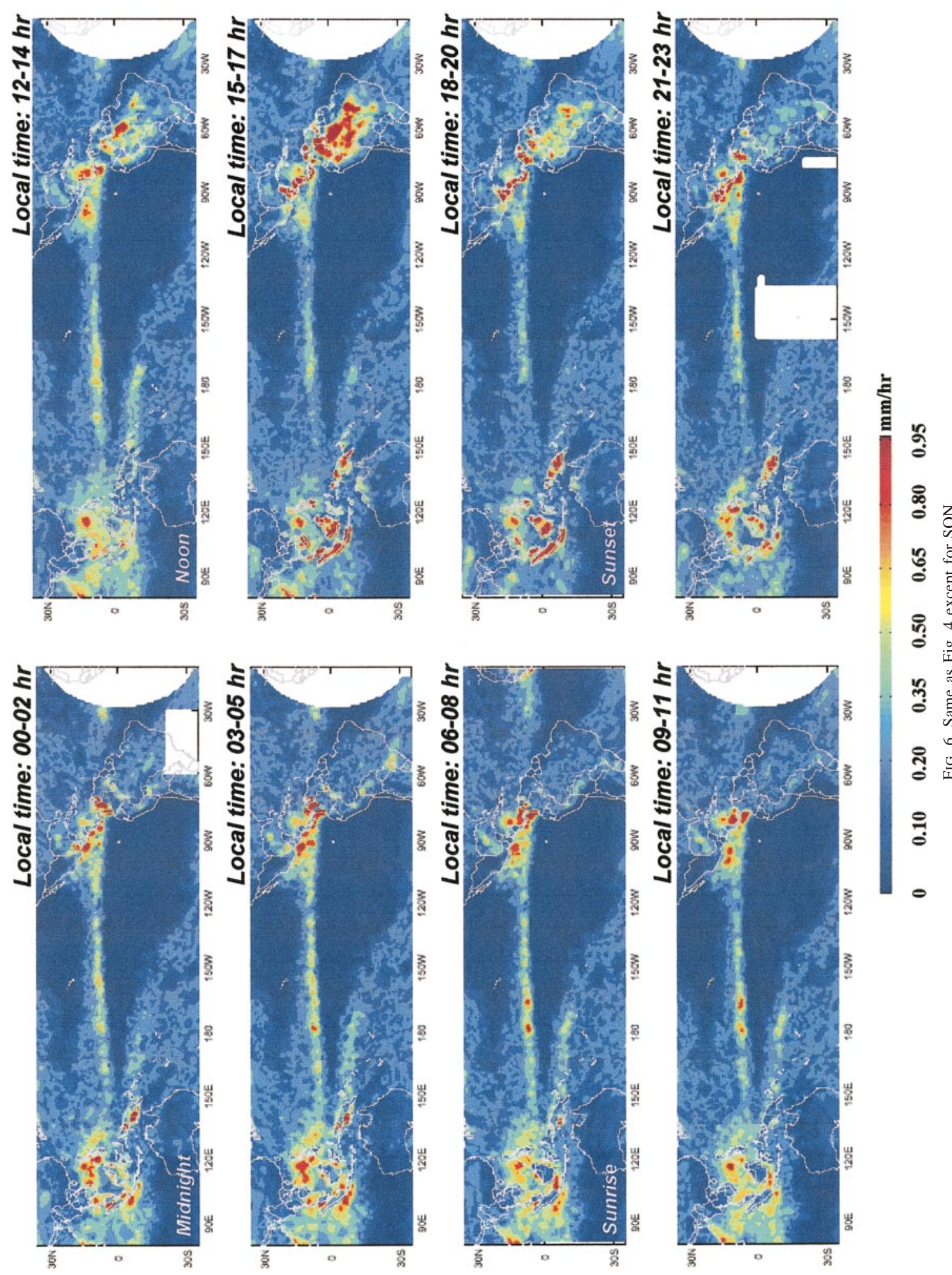

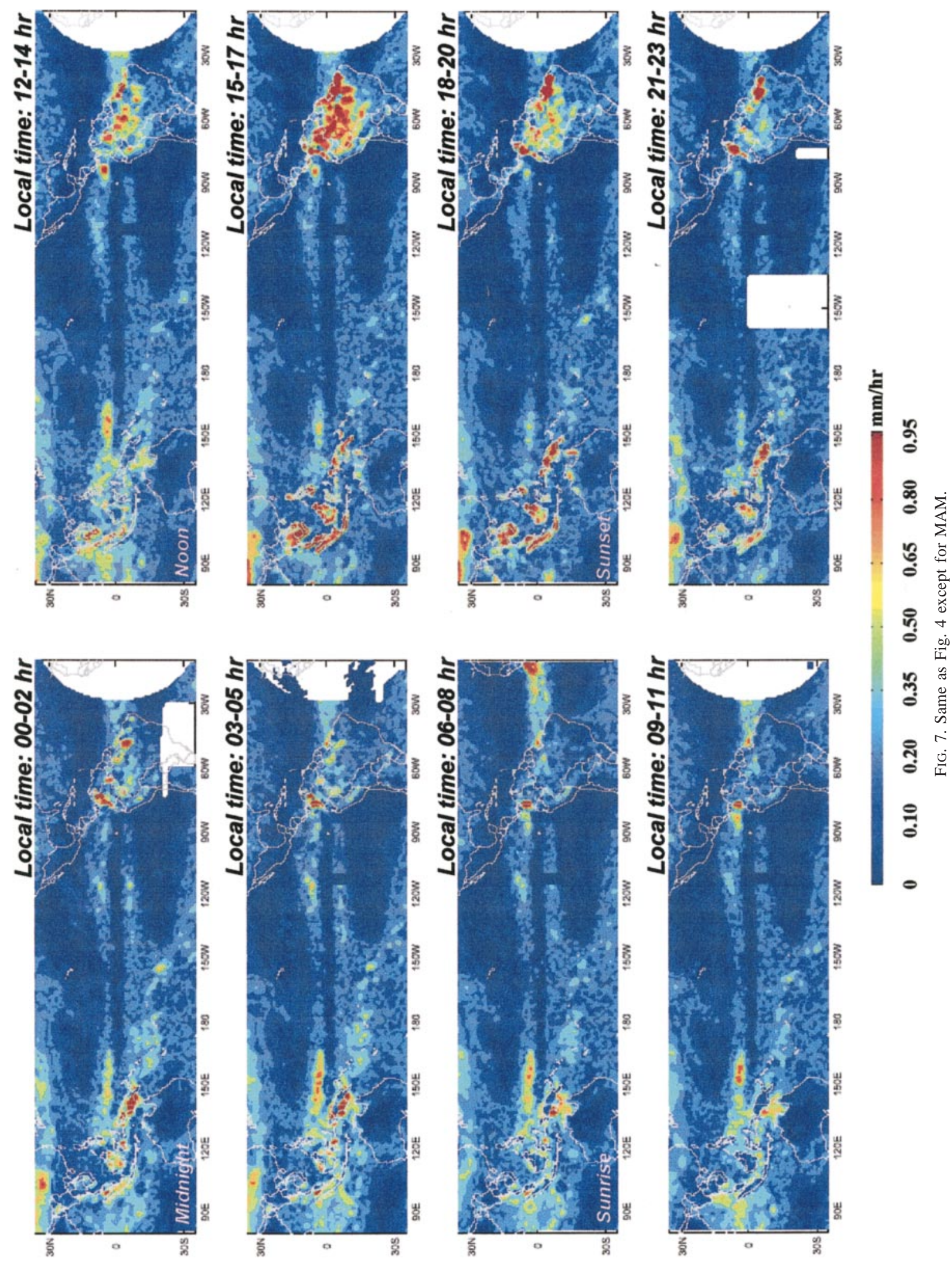
America, northern South America, and the Maritime Continent exhibit weaker but similar diurnal cycles of convective rainfall when compared to their summer seasons. The Pacific ITCZ, from $150^{\circ} \mathrm{W}$ to $180^{\circ}$, appears to experience enhanced convective rainfall during most of the day, but with an afternoon period of minimum activity from about 1500 to 2000 . This characteristic of convective rainfall in a portion of the ITCZ is quite similar to the austral summer character of rainfall within the SPCZ.

During the March, April, and May transition season (Fig. 7), the diurnal cycle remains quite pronounced around the equator, with midafternoon to near-midnight maxima occurring over the northern third of South America. The overland, afternoon-evening component of convection remains active over the Maritime Continent, but the early morning shift to oceanic convection is most distinct southwest of New Guinea and the Gulf of Carpentaria of Australia. There is also an indication of a very localized nocturnal maximum from midnight to about 0800 over the Strait of Malacca between Malaysia and Sumatra. Convective rainfall appears to organize routinely over Venezuela and northern Columbia during midafternoon to near midnight (0000-0200), and it translates toward the west, shifting offshore into the ocean during midmorning the next day and remaining distinct over the ocean until late afternoon (1500-1700). Interestingly, there is a distinct region of late-afternoon and nighttime convective rainfall apparent over China northeast of the Himalaya, which weakens after 0300 LST. There is a very distinct double ITCZ stretching across the entire tropical Pacific Ocean through this season. The northern ITCZ, from $140^{\circ}$ to $170^{\circ} \mathrm{E}$, stays quite active through most of the day, but with a distinct minimum occurring from 1800 to local midnight, somewhat similar to the behavior observed over the central Pacific ITCZ during the other transition season.

\section{b. Regional analyses}

\section{1) AMAZON}

To compare with the study of Garreaud and Wallace (1997), a PERSIANN rainfall map for the period 15001700 LST over Amazon during MAM is shown in Fig. 8a. As the patterns described in Garreaud and Wallace (1997), several parallel convection bands oriented from northwest to southeast are apparent in the figure. The four bands defined from the Andes Mountains (b1) to the northeastern coast of the Atlantic Ocean (b4) occur at the same locations and lengths as shown in Garreaud and Wallace (see their Fig. 3). The diurnal evolution of convection during MAM along two transects ( $\mathrm{DD}^{\prime}$ and $\mathrm{EE}^{\prime}$ ) are presented in Figs. $8 \mathrm{~b}-\mathrm{c}$. The patterns in time and space along the transects are very similar to Fig. 12 of Garreaud and Wallace (1997), which indicate that

1) over the western Atlantic Ocean, weak convections occurred during much of the day (Fig. 8b);
2) just inland from the Atlantic coast, a strong convective band (b4) occurs in the afternoon with a maximum at 1700 . This band appears to propagate to the southwest (Fig. 8b); and

3) convective bands b2 and b3 (Figs. 8b-c) are strongly linked to afternoon heating, maximizing from 1600 to 1800 .

\section{2) MeXico}

The diurnal cycle of PERSIANN-retrieved summer convective rainfall is presented in Fig. 9 as a local time cross section from west-southwest of Baja California to the western portion of the U.S. southern plains (see Fig. 10b of Garreaud and Wallace 1997). The diurnal accumulations were computed for $1^{\circ} \times 1^{\circ}$ boxes and hourly, giving much improved time and space resolution relative to the large-area seasonal plots discussed above. Over Sonora, Mexico, the area of active convection during the summer months is quite distinct, with little rainfall to the northeast (B) and almost none to the southwest (A). This illustrates the very focused character of the Mexican monsoon (Adams and Comrie 1997; Douglas et al. 1993; Negri et al. 1993). The diurnal signal for this region is very strong, with the vast majority of convective rainfall occurring from 1400 to 2200 during the afternoon and evening. There is no convective rainfall detected over the nearby eastern Pacific Ocean. According to Fig. 4, the only offshore shift of diurnal convection into the open Pacific Ocean occurs along the coasts of extreme southern Mexico and northern Central America.

\section{3) Northern Central America}

Plots of the overland and offshore diurnal cycles during the year are shown in Fig. 10 for northern Central America, that is, Guatemala (region 1), the Gulf of Tehuantepec (region 2), and over the Pacific Ocean south of Mexico (regions 3 and 4). Hourly average regional precipitation data (the regions' extents are $1^{\circ} \times 1^{\circ}$ ) for each month of the year are displayed in this figure. These regional plots also have higher time resolution than the large-area seasonal analyses (i.e., Figs. 4-7). Over Guatemala (region 1), the onset of the summer rainy season is very abrupt, with almost no precipitation occurring during May and very heavy afternoon and evening rains occurring during June. The well-known dry period of July and August (e.g., Hastenrath 1967) is well represented in the PERSIANN analyses, followed by the renewed heavy rains of September and October. The convective rains shift offshore into region 2 during both rainy periods. However, the time lags between maximum convection over land versus maximum convection over ocean are considerably different. During June, the overland maximum occurs from 1700 to 1800 , but the maximum rainfall over ocean does not occur until 0800 , 

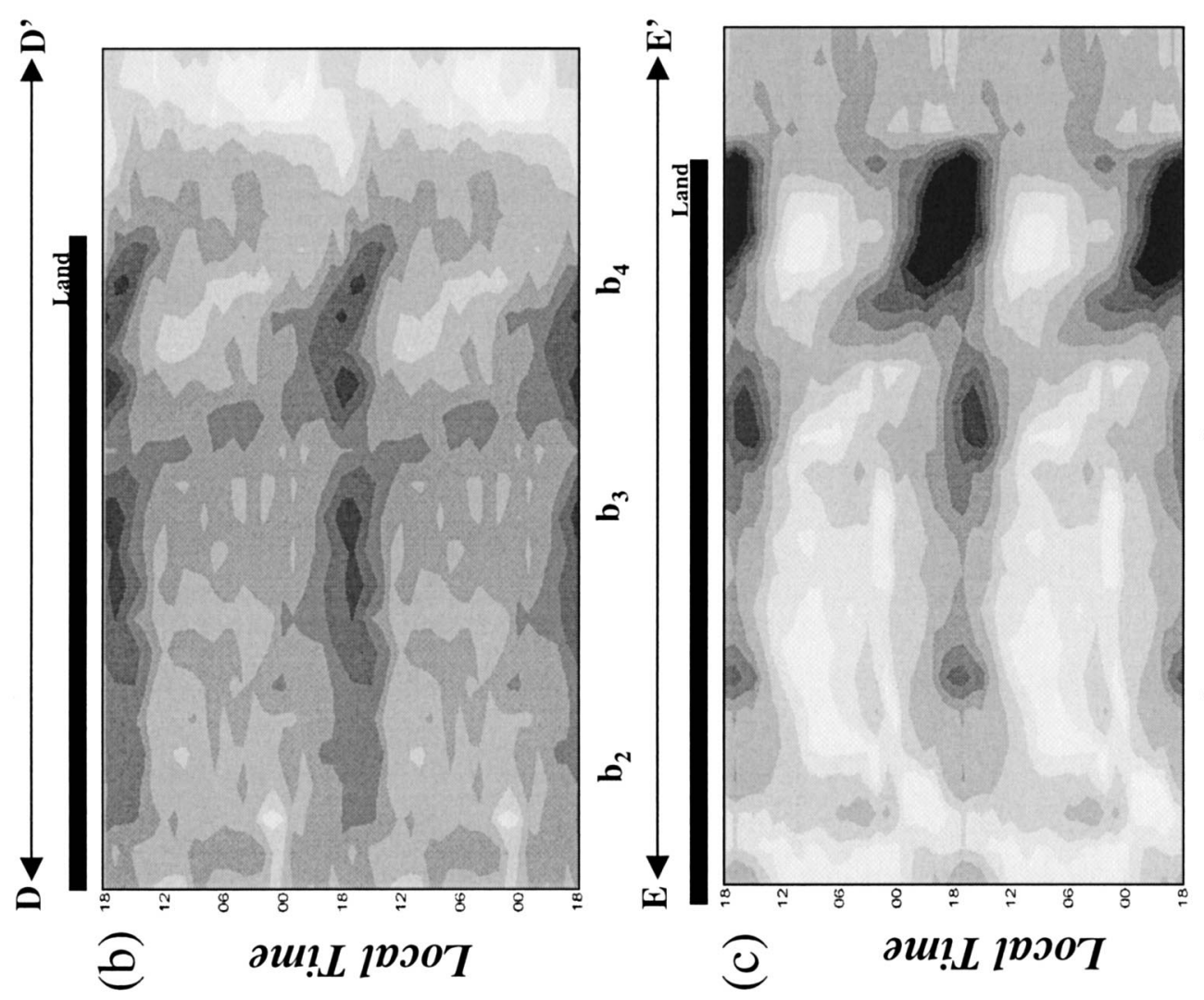

范

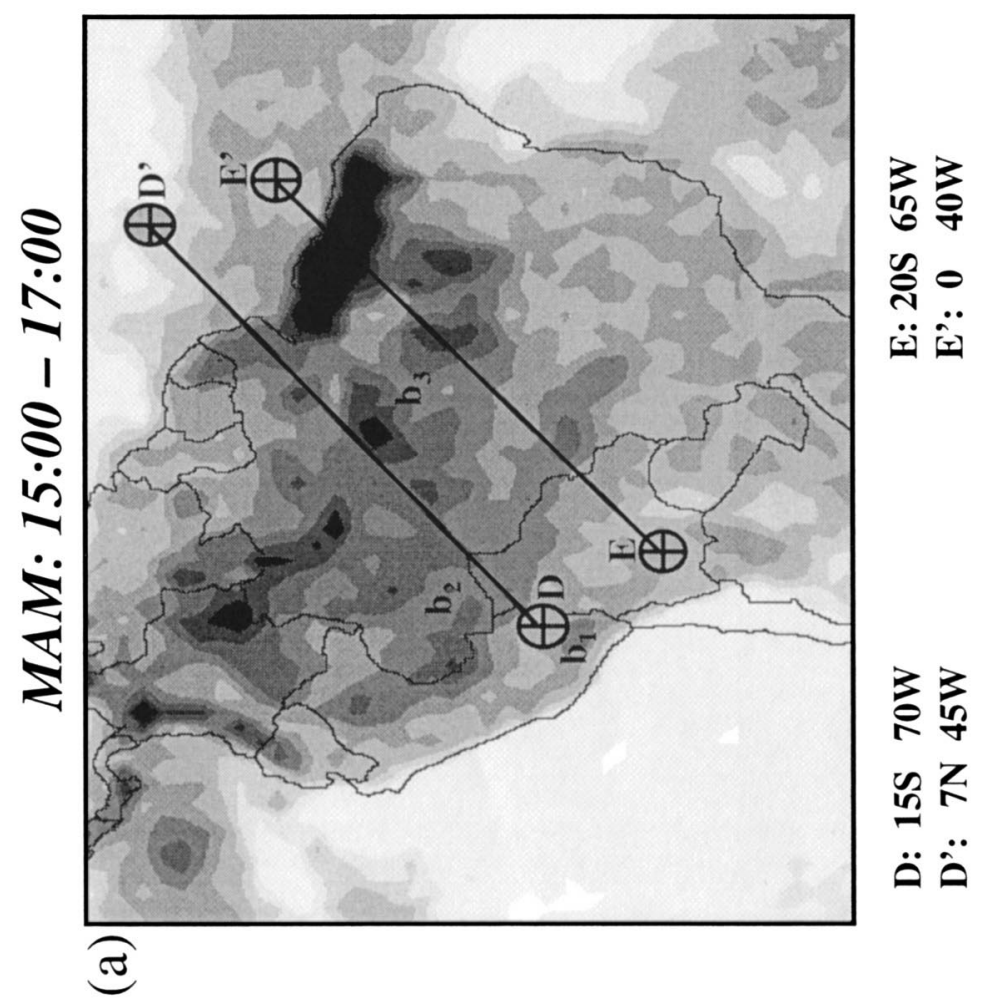



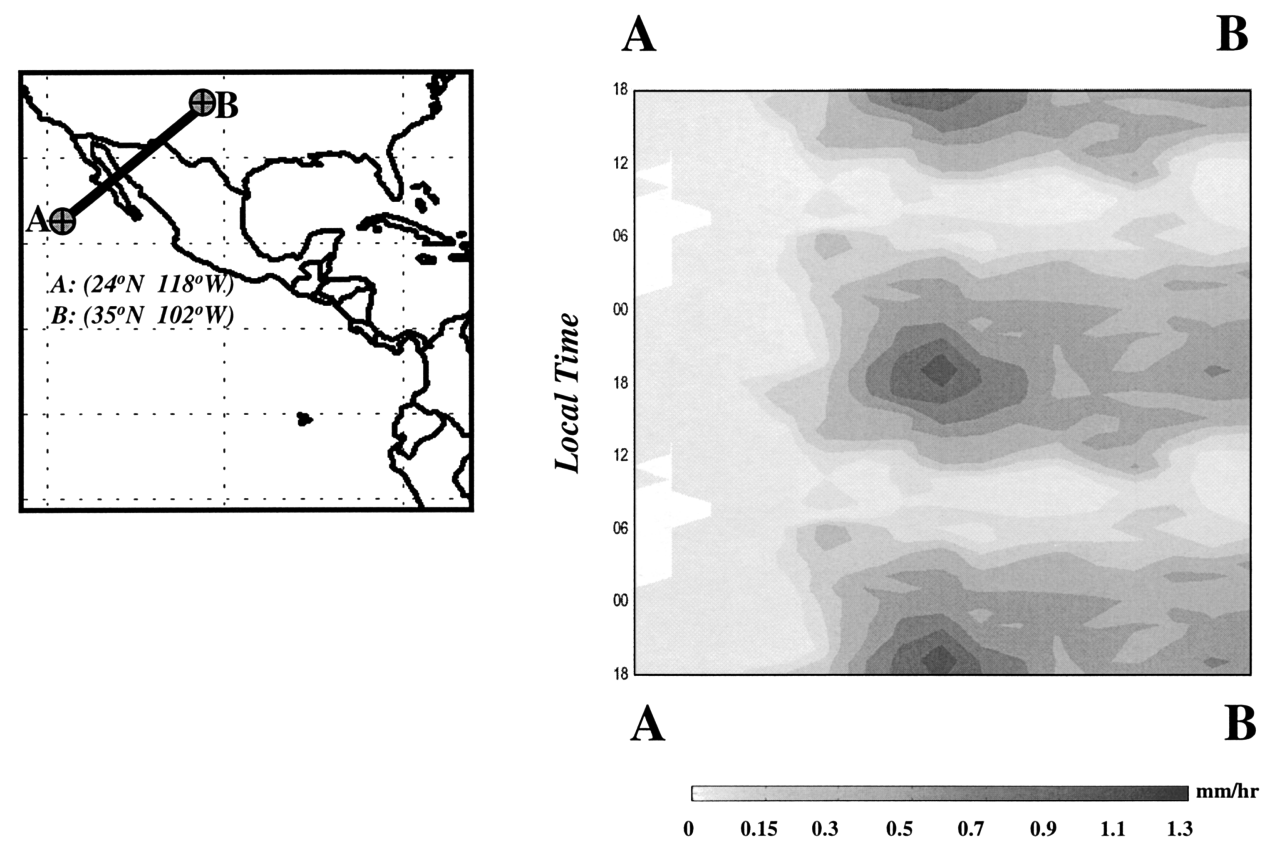

FIG. 9. Variation of summer (JJA) rainfall diurnal cycles along transect AB in northern Mexico [transect AB was defined by Garreaud and Wallace (1997) in their Fig. 10b].

about $14 \mathrm{~h}$ later. However, during September and October, the overland maximum in rainfall extends from 1700 to around 2300, which is both a longer period of heavy rains and a timing that is later in the afternoon and evening than the June activity. The ocean convection (region 2), however, begins much earlier, with a small maximum already present by 2200 , followed by a very strong maximum of nocturnal rains from 0100 through 0600 . The onset and weakening of the oceanic convection is very gradual in contrast to the abrupt onset and termination of the overland convection. It is possible that the September and October transition to ocean storms is related to organized convective outflows moving offshore, whereas the shift during June may be linked to the development of a larger-scale nocturnal land breeze.

Region 3 has a strong convective signal from near sunrise to local noon during June and September. Interestingly, there is almost no convection over this area during the period of strong rainfall in September and October that affects the Gulf of Tehuantepec. There is a very weak convective signal in region 4 during August after a 1-month dry period in July. The onset of intense convection in regions 3 and 4 does not occur until after 0900 in the morning.

\section{4) Caribbean Sea to Ecuador}

The summer diurnal cycle for a cross section along $80^{\circ} \mathrm{W}$ longitude off the coast of Ecuador into the middle of the Caribbean Sea is shown in Fig. 11. The diurnal signal for the Isthmus of Panama is very complex. Over land, the convective cycle is strongly focused in the early afternoon from 1400 to 1800 . The overwater portion of this region behaves much differently. There is a very strong morning to early afternoon period of convective rainfall that extends from around 0600 to 1500 to the south of the Isthmus of Panama. This region of convection is apparently linked to a westward shift of strong, later afternoon storms from northern Colombia (Fig. 4). Over the waters to the north of Panama, there is another maximum from about 0800 to local noon. The timing of this general precipitation cycle is puzzling. The offshore convection occurs during the morning to early afternoon, perhaps somehow related to large-scale land breezes moving westward from Bolivia. The timing of the precipitation south of Panama agrees well with the timing of high, cold cloud cover presented in Garreaud and Wallace (1997) for the Gulf of Panama. The diurnal patterns in this region are correlated with the maxima of convection over northern Colombia (Fig. 4).

\section{5) Calcutta, Bay of Bengal, and Malaysia}

The summer diurnal cycles of four regions of southern Asia are given in Fig. 12. Region 5, over India near Calcutta, exhibits a pronounced rainy period from June to August, with the remainder of the year being very dry. The convective storms occur mainly from local noon to 1500. In contrast, over the northern Bay of Bengal (region 6), the rainy season is highly concentrated during July and is characterized by an extended period of convective rainfall that extends from about 0100 just after midnight all the way through 1400 LST 

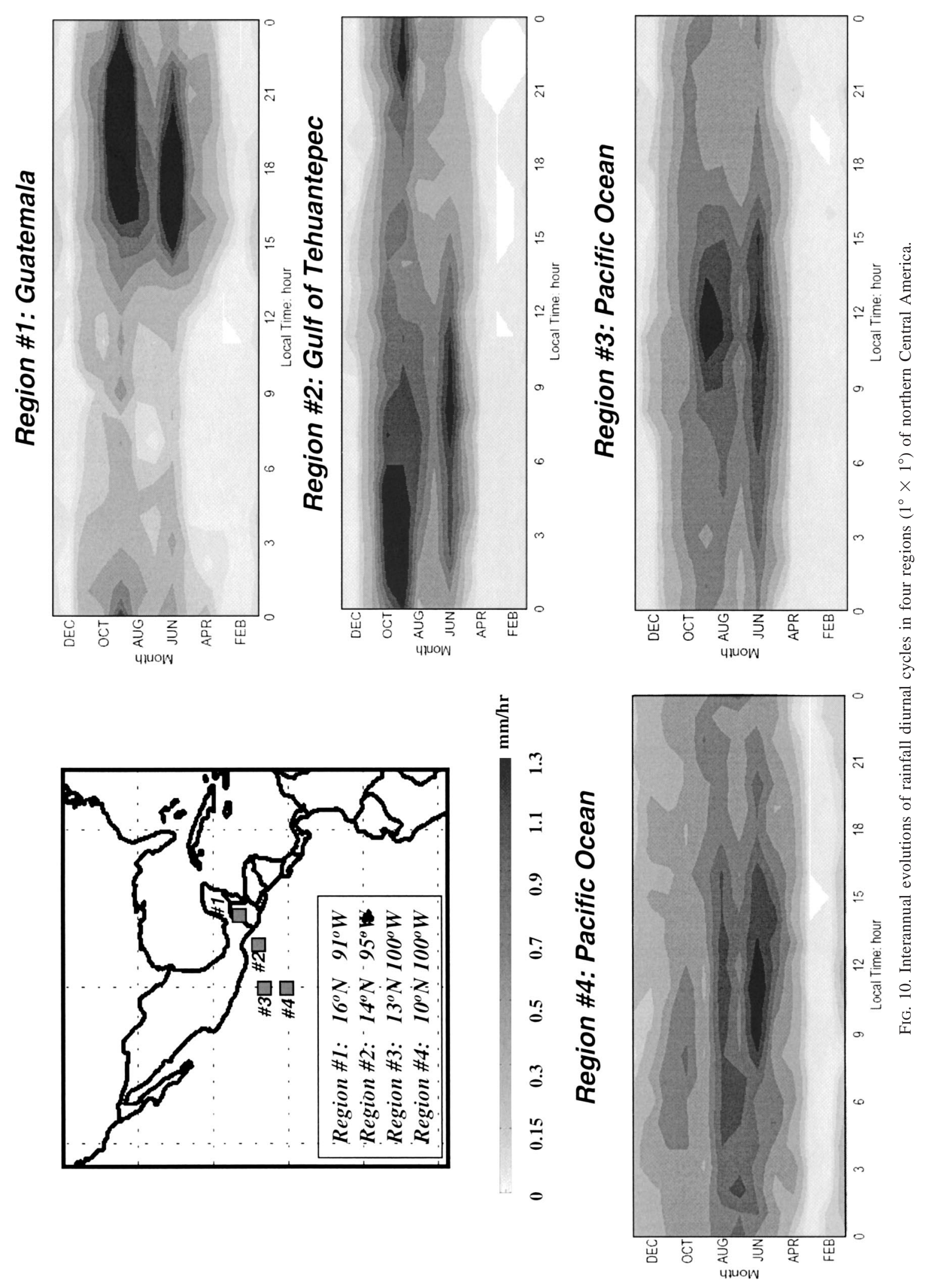

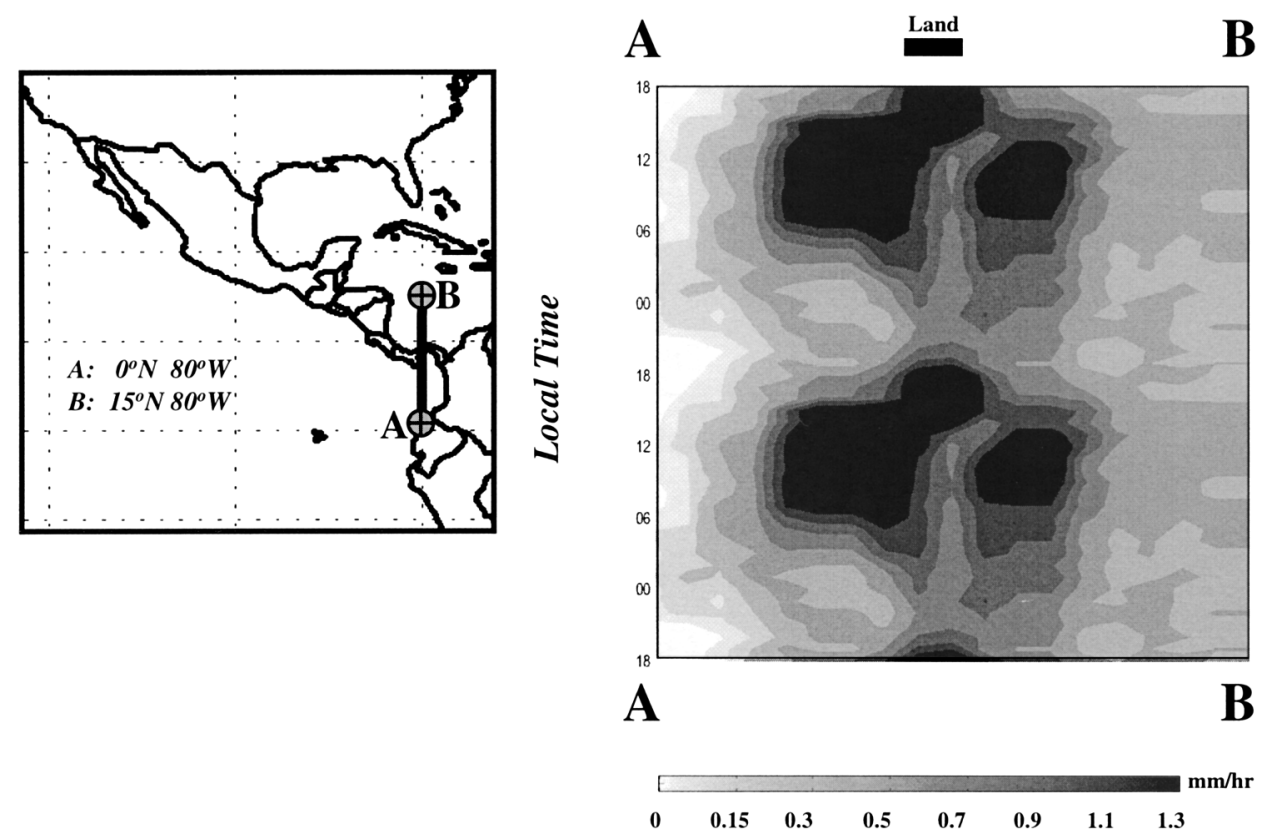

FIG. 11. Variation of summer (JJA) rainfall diurnal cycles along $80^{\circ} \mathrm{W}$ lon from the Gulf of Panama to the Caribbean Sea [transect AB was defined by Garreaud and Wallace (1997) in their Fig. 13a].

in the early afternoon. This unusual timing of the daily convective cycle shows the convective characteristics of the Indian monsoon (Yasunari 1990; Webster et al. 1996; Ding 1994) and may reflect converging land breezes and the shape of the Bay of Bengal itself.

Over Malaysia (region 8), there are two distinct rainy periods (March-May and September-November), with the occurrence of the convection strongly centered on 1500 during the midafternoon. Over the southern end of the Andaman Sea region, the seasonal and diurnal cycles of convection are very complex. There are four maxima during the year occurring in March, June, October, and very strongly in December. Each maximum occurs somewhere between 0100 and 0900 during the early morning hours. Thus, the ocean convection is lagged more than $9 \mathrm{~h}$ after the overland activity, perhaps indicating yet again the role of larger-scale land breezes in triggering the oceanic convection. Clearly, the maxima during June and December are not linked directly to afternoon storms over the land.

\section{6) Northern Australia}

The diurnal cycles over Arnhem Land in northern Australia (region 10) and over the Arafura Sea between Australia and New Guinea (region 9) are presented in Fig. 13. Over Arnhem Land, there is a strong late-afternoon maximum of convective rainfall, with distinct peaks in December and February surrounding a January period of reduced rainfall. The analyses are considerably different over the Arafura Sea. The dominant period of convective rainfall occurs in February, with weaker maxima occurring during December and April. The over-ocean maxima occur around 1000, but the February maximum extends from about 0700 through 1500 , much delayed relative to the convection over North America. The over-ocean maximum during April occurs during very dry conditions over the land.

\section{Discussion and summary}

An evaluation of the PERSIANN rainfall estimates and PERSIANN-derived diurnal analyses of tropical rainfall has been made using results from TRMM/TMI and PR surface rain products, TOGA radar rainfall estimates, and TOGA optical rain gauge data. This evaluation indicates that the PERSIANN analyses capture the major signals of diurnal variability of tropical rainfall. Errors in the timing of the maximums during the diurnal cycle are no more than 1-2 h. However, the deficiency of PERSIANN due to the contamination by very cold anvil cirrus clouds and the difficulty in detecting warm cloud rainfall could affect the quality of rain-rate estimates, as well as the derived diurnal features.

In the study region, tropical rainfall illustrates a variety of interesting patterns of diurnal cycle that vary seasonally and geographically. The results of JJA indicate a pronounced diurnal cycle over Central America, western Mexico, the extreme eastern Pacific Ocean, the Bay of Bengal, and the Maritime Continent/Southeast Asia. All of these regions are characterized by afternoon convection over land and nighttime to morning convection and rainfall over the oceans. Over extreme southern Mexico and northern Central America, intense convection forms over the land from 1500 to 2300 and 

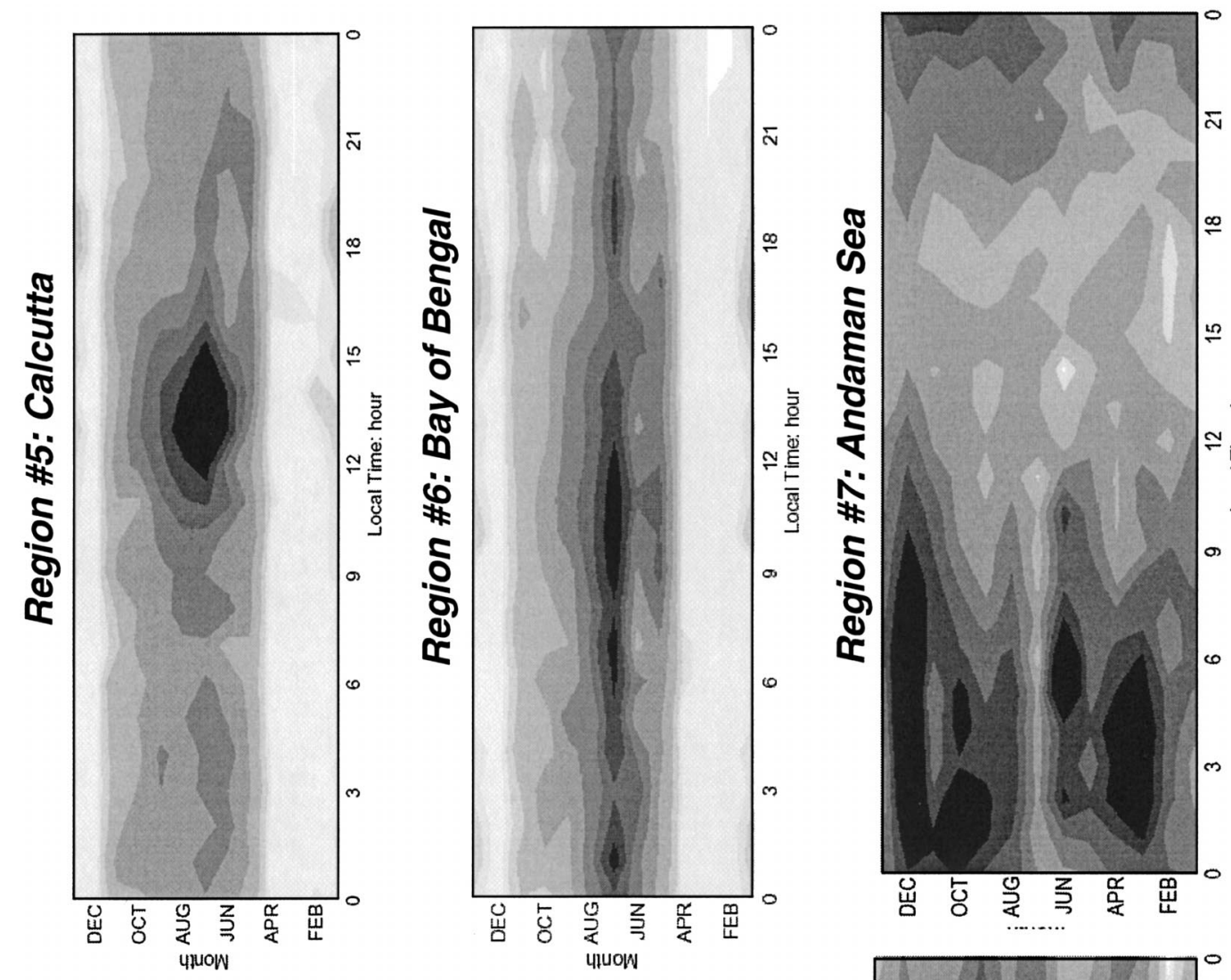

물 


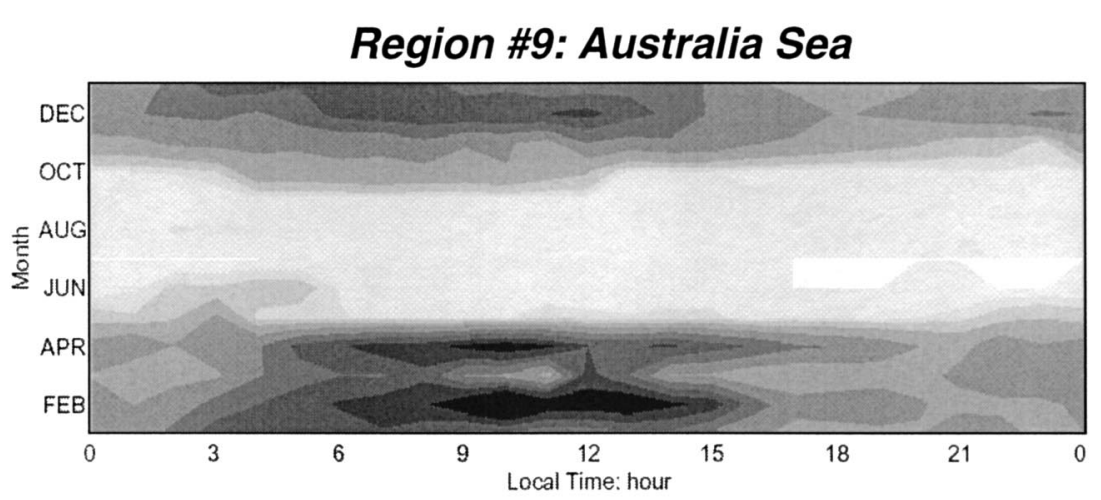

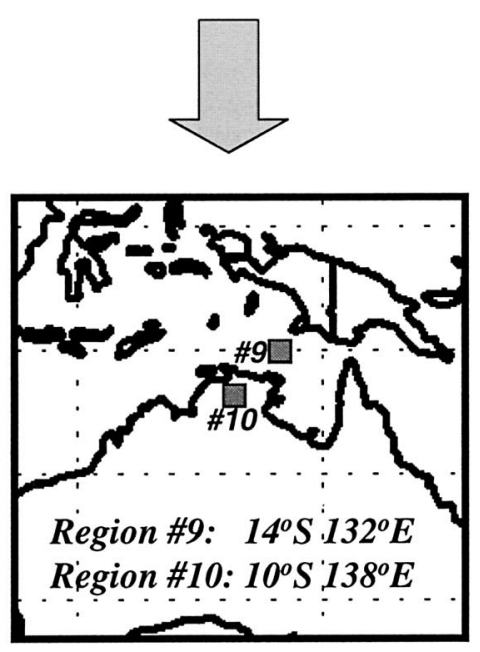
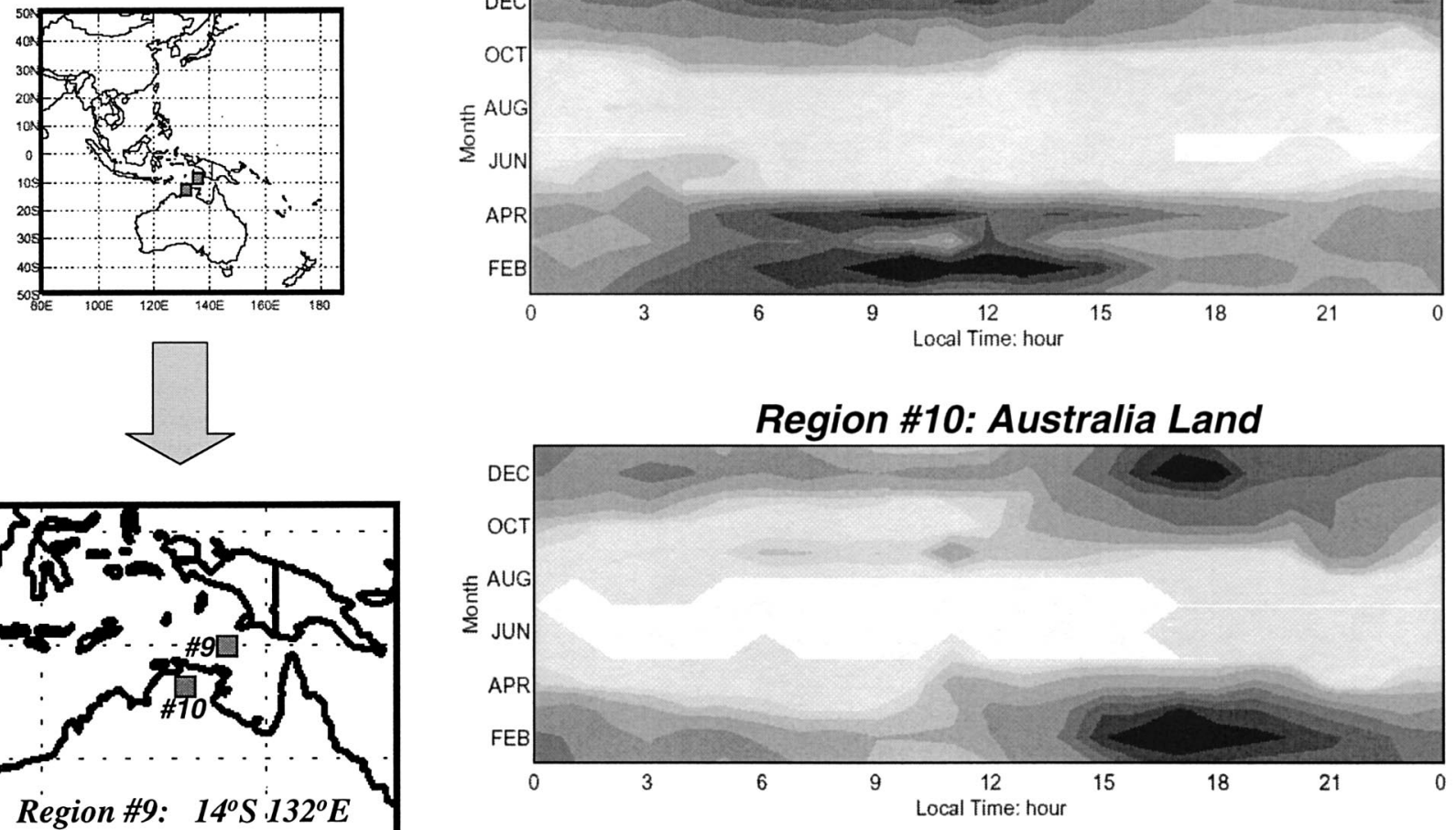

FIG. 13. Interannual evolutions of rainfall diurnal cycles in two regions $\left(1^{\circ} \times 1^{\circ}\right)$ of northern Australia. then shifts offshore after local midnight off the southwestern coast of Mexico. This convection moving offshore from southern Mexico appears to distort the ITCZ into a broad north-south zone of active convection extending westward to about $120^{\circ} \mathrm{W}$. It is only this fareastern Pacific Ocean region of the ITCZ that displays a strong diurnal signal in the boreal summer season. During DJF, Brazil, the northern two-thirds of South America, northern Australia, southwest of Borneo, New Guinea, and the Gulf of Carpentaria exhibit strong daytime convective rainfall over land, and then new convection develops strongly offshore. The South Pacific convergence zone (SPCZ) appears to stay active through most of the day, with only a mid to late afternoon (15002000 LST) decrease in convective rainfall apparent. The pronounced diurnal cycles illustrated provide useful information for the study of climate systems. The figures shown capture convective features of synoptic climate systems that are related to forcings of upward motion that are occurring on a variety of scales.

In this paper, only the most outstanding regions of diurnal variability of tropical rainfall have been addressed. However, this study clearly indicates that nonambiguous determination of the daily convective rainfall cycle requires high spatial and temporal resolutions of precipitation data. The current results, limited to only 1 year of tropical rainfall data, for the monthly mean of rainfall diurnal cycles at hourly and $1^{\circ} \times 1^{\circ}$ resolutions are plausible and in agreement with past studies. Higher resolutions are, of course, needed to study the local-scale variability. Because the study period (August 1998-June 1999) took place during the transition year of global climate from strong El Niño to strong La Niña conditions, features illustrated in this study could be different from results based on multiyear data. With the availability of global infrared satellite datasets (Janowiak et al. 2001) and TRMM data, 3-yr global tropical rainfall analyses are computed, while improving the quality of PERSIANN rainfall estimation. To assist interested readers, the relevant data will be provided upon request.

Acknowledgments. This research was partially funded by the NASA EOS-IDS Grant (NAG5-11044), NASA Grant (NAG5-8503 HyDIS), NASA TRMM Grant (NAG5-9549), and by Sustainability of semi-Arid Hydrology and Riparian Area (SAHRA) under the STC Program of NSF (Agreement No. EAR-9876800). We would like to thank A.J. Negri and L. Xu of NASA GSFC for providing the TOGA radar rainfall. Thanks 
are also extended to Ms. Corrie Thies for her careful reading and editing of the manuscript.

\section{REFERENCES}

Adams, D. K., and A. C. Comrie, 1997: The North American monsoon. Bull. Amer. Meteor. Soc., 78, 2197-2213.

Adler, R. F., and A. J. Negri, 1988: A satellite infrared technique to estimate tropical convective and stratiform rainfall. J. Appl. Meteor., 27, 30-51.

,-- , P. R. Keehn, and I. M. Hakkarinen, 1993: Estimation of monthly rainfall over Japan and surrounding waters from a combination of low-orbit microwave and geosynchronous IR data. J. Appl. Meteor., 32, 335-356.

— G. J. Huffman, and P. R. Keehn, 1994: Global rain estimates from microwave adjusted geosynchronous IR data. Remote Sens. Rev., 11, 125-152.

Anagnostou, E. N., and C. Morales, 2002: Rainfall estimation from TOGA radar observations during TRMM-LBA field campaign. J. Geophys. Res., in press.

— A. J. Negri, and R. F. Adler, 1999: A satellite infrared technique for diurnal rainfall variability studies. J. Geophys. Res., 104 (D24), 31 477-31 488.

Brier, G. W., 1965: Diurnal and semi-diurnal atmospheric tide in relation to precipitation variations. Mon. Wea. Rev., 93, 93-100.

— to pressure and tidal variations. Quart. J. Roy. Meteor. Soc., 95, $120-147$.

Chang, A. T. C., L. S. Chiu, and G. Yang, 1995: Diurnal cycle of oceanic precipitation from SSM/I data. Mon. Wea. Rev., 123, $3371-3380$.

Dai, A., 2001: Global precipitation and thunderstorm frequency. Part II: Diurnal variations. J. Climate, 14, 1112-1128.

_ , F. Giorgi, and K. E. Trenberth, 1999: Observed and modelsimulated diurnal cycles of precipitation over the contiguous United States. J. Geophys. Res., 104, (D6), 6377-6402.

Ding, Y., 1994: Monsoon over China. Kluwer Academic, 419 pp.

Douglas, M. W., R. Maddox, K. Howard, and S. Reyes, 1993: The Mexican monsoon. J. Climate, 6, 1665-1677.

Garreaud, R. D., and J. M. Wallace, 1997: The diurnal march of convective cloudiness over the Americas. Mon. Wea. Rev., 125, $3157-3171$.

Gray, W. M., and R. W. Jacobson, 1977: Diurnal variation of deep cumulus convection. Mon. Wea. Rev., 105, 104-188.

Hastenrath, S. L., 1967: Rainfall distribution and regime in Central America. Arch. Meteor. Geophys. Bioklimatol. Ser. B, 15, 201241.

Hsu, K., X. Gao, S. Sorooshian, and H. V. Gupta, 1997: Precipitation estimation from remotely sensed information using artificial neural networks. J. Appl. Meteor., 36, 1176-1190.

Janowiak, J. E., P. A. Arkin, and M. Morrissey, 1994: An examination of the diurnal cycle in oceanic tropical rainfall using satellite and in situ data. Mon. Wea. Rev., 122, 2296-2311.

- R. J. Joyce, and Y. Yarosh, 2001: A real-time global half-hourly pixel-resolution infrared dataset and its applications. Bull. Amer. Meteor. Soc., 82, 205-217.

Johnson, R. H., T. M. Rickenbach, S. A. Rutledge, P. E. Ciesielski, and W. H. Schubert, 1999: Trimodal characteristics of tropical convection. J. Climate, 12, 2397-2418.

Kraus, E. B., 1963: The diurnal precipitation change over the sea. $J$. Atmos. Sci., 20, 546-551.

Mapes, B. E., and R. A. Houze Jr., 1993: Cloud clusters and superclusters over the oceanic warm pool. Mon. Wea. Rev., 121, 13981415.

Meisner, B., and P. Arkin, 1987: Spatial and annual variations in the diurnal cycle of large-scale tropical convective cloudiness and precipitation. Mon. Wea. Rev., 115, 2009-2032.

Negri, A. J., R. F. Adler, R. A. Maddox, K. W. Howard, and P. R. Keehn, 1993: A regional rainfall climatology over Mexico and the southwest United States derived from passive microwave and geosynchronous infrared data. J. Climate, 6, 2144-2161.

$\ldots, \ldots$, E. Nelkin, and G. Huffman, 1994: Regional rainfall climatologies derived from Special Sensor Microwave Imager (SSM/I) data. Bull. Amer. Meteor. Soc., 75, 1165-1182.

- E. N. Anagnostou, and R. F. Adler, 2000: A 10-year climatology of Amazonian rainfall derived from passive microve satellite observations. J. Appl. Meteor., 39, 42-56.

— - L. Xu, and R. F. Adler, 2002: A TRMM-calibrated infrared rainfall algorithm applied over Brazil. J. Geophys. Res., in press.

Randall, D. A., Harshvardhan, and D. A. Dazlich, 1991: Diurnal variability of the hydrologic cycle in a general circulation model. J. Atmos. Sci., 48, 40-62.

Riehl, H., 1947: Diurnal variation of cloudiness over the subtropical Atlantic Ocean. Bull. Amer. Meteor. Soc., 28, 37-40.

Sharma, A. K., A. T. C. Chang, and T. T. Wilheit, 1991: Estimation of the diurnal cycle of oceanic precipitation from SSM/I data. Mon. Wea. Rev., 119, 2168-2175.

Shin, K. S., G. R. North, Y. S. Ahn, and P. A. Arkin, 1990: Time scales and variability of area-average tropical oceanic rainfall. Mon. Wea. Rev., 118, 1507-1516.

Sorooshian, S., K. Hsu, X. Gao, H. V. Gupta, B. Imam, and D. Braithwaite, 2000: Evaluation of PERSIANN system satellite-based estimates of tropical rainfall. Bull. Amer. Meteor. Soc., 81, 20352046.

Wallace, J. M., 1975: Diurnal variations in precipitation and thunderstorm frequency over the conterminous United States. Mon. Wea. Rev., 103, 585-598.

Webster, P. J., C. A. Clayson, and J. A. Curry, 1996: Clouds, radiation, and the diurnal cycle of sea surface temperature in the tropical western Pacific. J. Climate, 9, 1712-1730.

Xu, L., X. Gao, S. Sorooshian, P. A. Arkin, and B. Imam, 1999: A microwave infrared threshold technique to improve the GOES precipitation index. J. Appl. Meteor., 38, 569-579.

$\ldots,-, \ldots$, and B. Imam, 2000: Parameter estimation of GOES precipitation index at different calibration time scales. J. Geophys. Res., 105, 20 131-20 143.

Yasunari, T., 1990: The impact of the Indian monsoon on the coupled atmosphere/ocean system in the tropical Pacific. Meteor. Atmos. Phys., 44, 29-41. 